\title{
Biological characterization of sheep kidney-derived mesenchymal stem cells
}

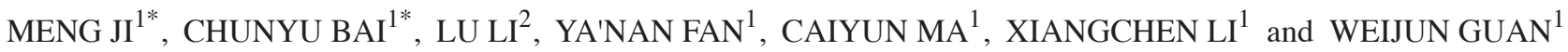 \\ ${ }^{1}$ Department of Animal Genetic Resources, Institute of Animal Science, Chinese Academy of Agricultural \\ Sciences, Beijing 100193; ${ }^{2}$ Department of Animal Genetic Resources, College of Animal Science \\ and Technology, Agricultural University of Hebei, Baoding, Hebei 071000, P.R. China
}

Received July 7, 2015; Accepted September 1, 2016

DOI: $10.3892 / \mathrm{etm} .2016 .3902$

\begin{abstract}
The aim of the present study was to isolate, culture and characterize sheep metanephric mesenchymal stem cells (MMSCs). The MMSCs were isolated from the kidney tissue of six-week-old sheep fetus. This study investigated whether primary MMSCs could be grown for 26 passages and expressed Oct-4, which is involved in the self-renewal of undifferentiated pluripotent stem cells. The MMSCs also expressed the renal lineage marker gene PAX2, and mesenchymal cell marker genes CD44, FN1 and VIM. Expression of these genes was detected using immunofluorescence and reverse transcription-polymerase chain reaction assays. Additionally, we observed that the MMSCs are able to differentiate into adipocyte, hepatocyte and chondrocyte cells. Karyotype analyses showed that these cells were 95\% diploid and thus differentiated. These results indicate that the MMSCs obtained from sheep fetuses possessed certain characteristics of multipotent stem cells. Therefore, MMSCs may potentially offer utility for tissue engineering and cellular transplantation therapy, and further studies are required to investigate these uses.
\end{abstract}

\section{Introduction}

Mesenchymal stem cells (MSCs) possess a strong proliferative capacity and are able to differentiate into endothelium (1), adipocytes (1-3), neurons $(2,4)$, osteoblasts $(1,3,5)$ and myoblasts $(5,6)$, which were first identified in bone marrow. In recent years, MSCs have been discovered in amniotic fluid,

Correspondence to: $\mathrm{Dr}$ Xiangchen Li or Professor Weijun Guan, Department of Animal Genetic Resources, Institute of Animal Science, Chinese Academy of Agricultural Sciences, 2 Yuanmingyuan Road, Beijing 100193, P.R. China

E-mail: xcli863@126.com

E-mail:wjguan86@iascaas.net.cn

*Contributed equally

Key words: sheep, metanephric mesenchyme stem cells, biological characteristics, culture, induce muscles, umbilical cord blood, dermis and other tissues (2,7-9). Although the most abundant source of MSCs is bone marrow, they can be obtained from other tissues, including the kidneys (10). Prior studies have indicated that metanephric mesenchyme (MM) contains embryonic renal stem cells which can generate all the epithelial cells of the nephron (11-13).

Renal disease is a common clinical disease and is growing worldwide. There are no effective therapy modes to treat renal disease, but continuous renal replacement therapy is typically performed at the end stage of the disease (14). MSCs may be capable of reversing kidney injury (15). Transplanted MSCs are localized at targeted tissue supporting the notion that the efficacy of MSCs in treating diseases is independent of engraftment and differentiation (16); however, more research is required.

The kidneys originate from the intermediate mesoderm (IM), located between the paraxial and lateral mesoderms, of the early embryonic germ layer (17). In mammals, the IM finally develops three types of kidneys: Pronephros, mesonephros and the metanephros (18). The human definitive kidneys begin to develop early in the fifth week and become functional at approximately four weeks later (19). The mammalian adult kidney is developed from the MM and the ureteric bud, which forms from the IM (10). The reciprocal interaction between the $\mathrm{MM}$ and the ureteric bud is a central step in kidney development. The MM is differentiated into epithelialized nephrons and interstitium by the ureteric bud induction, while the MM induces the ureteric bud to differentiate into the lower urinary tract (10).

Current studies of stem cells focus on humans, mouse, rat and other mammals, but limited research has been conducted involving sheep $(10,12,13,17,19)$. The purpose of the present study was to investigate the isolation and culture process of MMSCs in vitro, which were isolated from six-week-old embryonic sheep kidney tissues, and to study their biological characterization.

\section{Materials and methods}

Experimental materials. A total of 2 one-year-old demale Ovis aries sheep, weighing 74 and $76 \mathrm{~kg}$, were supplied by the Chinese Academy of Agriculture Science farm. All 
animal experiments were performed in accordance with the guidelines established by the Institutional Animal Care and Use Committee at Chinese Academy of Agriculture Sciences. All cell culture media and supplements were obtained from Sigma-Aldrich (Merck KGaA, Darmstadt, Germany), unless stated otherwise. All cell culture plates were provided by Wuxi Nest Biotechnology Co., Ltd. (Wuxi, China). Animals were sacrificed by intraperitoneal injection of sodium pentobarbital (100 mg/kg; Sigma-Aldrich; Merck Millipore). The study was approved by the Institutional Animal Care and Use Committee of the Chinese Academy of Agricultural Sciences (Beijing, China).

Isolation and culture of the MMSCs from fetal kidney. The sheep fetuses ( $n=4 ; n=2$ at six weeks-old, $n=2$ at ten weeks-old) were collected after caesarean section (1-2 month) under sterile conditions. The kidney tissues were isolated from the fetus and washed three times by phosphate-buffered saline (PBS) without calcium and magnesium. The kidney tissues were cut into $\sim 1 \mathrm{~cm}^{2}$ pieces, then digested with $0.2 \%(\mathrm{w} / \mathrm{v})$ collagenase (Gibco; Thermo Fisher Scientific, Inc., Grand Island, NY, USA) in DMEM/F12 with $10 \%$ fetal bovine serum (FBS; Gibco; Thermo Fisher Scientific, Inc.) for $30 \mathrm{~min}$ at $37^{\circ} \mathrm{C}$. Then the undigested tissues were incubated with $0.25 \%$ (w/v) trypsin and $0.02 \%$ (w/v) EDTA (Gibco) for $15 \mathrm{~min}$. In addition, neutralized the enzymatic activity was neutralized using an equal volume of FBS. The digested tissues and digestive juice were filtrated using a 74- $\mu \mathrm{m}$ cell strainer , and the cell suspension was centrifuged at $200 \times \mathrm{g}$ for $8 \mathrm{~min}$ at room temperature. The bottom cells were resuspended in complete medium [DMEM/F12, 10\% (v/v) FBS and $10^{4} \mathrm{IU} / \mathrm{ml}$ penicillin/streptomycin]. After counting, cells were plated into a $60-\mathrm{mm}$ culture dish and incubated at $37^{\circ} \mathrm{C}$ in $5 \% \mathrm{CO}_{2}$. Cells were washed twice with PBS to remove non-adherent cells after $24 \mathrm{~h}$ later. When cultures reached $80 \%$ confluence, cells were digested with warmed trypsin $(0.25 \%$ trypsin and $0.02 \%$ EDTA) and then subcultured onto fresh culture plates. After 3-4 passages $(\mathrm{P})$ cells were purified.

Immunofluorescent detection of cell markers. Cultures of MMSCs at different passages were seeded $\left(0.5 \times 10^{5}\right.$ cells per $1 \mathrm{~cm}^{2}$ glass coverslip) on glass coverslips coated with poly-L-lysine. For immunofluorescent assay analysis, the sheep MMSCs were fixed with $4 \%$ paraformaldehyde for 15 min and washed three times (5 min per wash) with PBS. After cultures reached $70 \%$ confluence, the cells were permeabilized with $0.25 \%$ Triton X-100 for 10 min. Cells were washed three times ( 5 min per wash) with PBS, then blocking with $10 \%$ goat serum was performed in $1 \mathrm{~h}$ prior to the incubation with primary antibodies. The cells were incubated with the following primary antibodies: Anti-Oct-4 (cat. no. ab27985), anti-CD44 (cat. no. ab157107) (both purchased from Abcam, Cambridge, MA, USA), anti-FN1 (cat. no. bs-4859R), anti-PAX2 (cat. no. bs-1187R), anti-VIM (cat.no. bs-3472R) and anti-CD34 (cat. no. bs-8996R) (all 1:100; Beijing Biosynthesis Biotechnology Co., Ltd., Beijing, China) at $4^{\circ} \mathrm{C}$ overnight. Cells were washed three times ( 5 min per wash) with PBS, followed by with fluorescein isothiocyanate-conjugated goat anti-rabbit (cat. no. ZF-0314) or Cy5-conjugated goat anti-rabbit (cat. no. ZF-0516) secondary antibodies (1:100;
Beijing Zhongshan Golden Bridge Biotechnology, Co., Ltd., Beijing) in dark for $1 \mathrm{~h}$ at room temperature. Finally, $10 \mu \mathrm{g} / \mathrm{ml}$ DAPI (Solarbio Biotechnology Co., Ltd., Beijing, China) was used to label the cell nuclei for $15 \mathrm{~min}$, then images were captured using a fluorescence microscope (TE-2000-E; Nikon Corporation, Tokyo, Japan). PBS was used as a substitute for primary antibodies for technical controls.

Reverse transcription-polymerase chain reaction (RT-PCR) analysis. MMSCs at different passages were collected and total RNA was extracted using TRIzol reagent (Invitrogen; Thermo Fisher Scientific, Inc., Carlsbad, CA, USA). DNase I (Solarbio Biotechnology Co., Ltd.) was used to digest the potential contamination of genomic DNA. Total RNA $(2.0 \mu \mathrm{g})$ was reverse transcribed into cDNA using an RNA PCR kit, version 3.0 (Takara Biotechnology, Co., Ltd., Dalian, China). Primer sequences are listed in Table I. The PCR reaction was performed by the PCR Master Mix Kit (Takara Biotechnology, Co., Ltd.), according to the manufacturer's instructions. PCR analyses were performed in 50- $\mu$ l volumes containing $25 \mu \mathrm{l} 2 \mathrm{X}$ PCR Mix, $15 \mu \mathrm{lddH}_{2} \mathrm{O}, 5 \mu \mathrm{l}$ template cDNA and $2.5 \mu \mathrm{l}$ each of forward and reverse primers. Cycling conditions consisted of an initialization step at $94^{\circ} \mathrm{C}$ for 5 min, then 35 cycles of a denaturation step at $94^{\circ} \mathrm{C}$ for $30 \mathrm{sec}$, annealing step at $50-60^{\circ} \mathrm{C}$ for $30 \mathrm{sec}$, elongation step at $72^{\circ} \mathrm{C}$ for $30 \mathrm{sec}$ and final elongation step at $72^{\circ} \mathrm{C}$ for $5 \mathrm{~min}$. The PCR products were visualized by electrophoresis using $2.0 \%(\mathrm{w} / \mathrm{v})$ agarose gels.

Karyotype analysis. Chromosomes were prepared, fixed and stained according to a method described previously (20). The sheep MMSCs were incubated in $0.5 \mu \mathrm{g} / \mathrm{ml}$ colcemid (Sigma-Aldrich; Merck Millipore) at $37.5^{\circ} \mathrm{C}$ for $6 \mathrm{~h}$, then the cells were digested with $0.25 \%$ trypsin. The centrifuged cells (200 x $g, 8 \mathrm{~min}$ at room temperature) were resuspended in $0.075 \mathrm{M} \mathrm{KCl}$ solution at $37^{\circ} \mathrm{C}$ for $30 \mathrm{~min}$. Finally, the cells were fixed in 3:1 methanol: glacial acetic acid and dropped in the frozen glass slides, stained with Giemsa. The cell chromosome numbers were counted under an oil immersion objective. Relative length, centromeric index and arm ratio were analyzed according to the protocol of Sun et al (21) and Kawarai et al (22).

Colony-forming cell analysis. The sheep MMSCs from P4, 10 and 16 were cultured in $60-\mathrm{mm}$ plates at a density of 100 cells/well for two weeks and the numbers of colony-forming units were counted. The cloning efficiencies were calculated as follows: Colony-forming unit number/100 x 100\% (2).

Growth kinetics. The sheep MMSCs from P5, 10 and 16 were plated in 24-well microplates at a density of $1 \times 10^{4}$ cells/well for growth kinetics analysis for seven days. Growth curves were plotted according to the mean values (1). The population doubling time (PDT) was computed as follows: PDT $=\left(t-t_{0}\right)$ $\log _{2} /\left(\log N_{t}-\log N_{0}\right)$, where $t=$ termination time of culture, $t_{0}=$ start time of culture, $N_{t}=$ the final number of cells in culture and $N_{0}=$ initial number of cells in culture.

Adipogenic differentiation. The sheep MMSCs were seeded in six-well plates at a density of $2 \times 10^{4}$ cells/well. Upon reaching $60-70 \%$ confluence, cells in the control group were maintained 
Table I. Primer sequences used for reverse transcription-polymerase chain reaction.

\begin{tabular}{|c|c|c|c|}
\hline Gene & Primer sequence & Product length (bp) & Temperature $\left({ }^{\circ} \mathrm{C}\right)$ \\
\hline OCT4 & $\begin{array}{l}\text { F: 5'-GGACACCTCGCTTCTGACT-3' } \\
\text { R: 5'-GGCTCCAGCTTCTCCTTGT-3' }\end{array}$ & 386 & $\begin{array}{l}59.03 \\
59.32\end{array}$ \\
\hline VIM & $\begin{array}{l}\text { F: 5'-CAGGAGGAGATGCTTCAGAGA-3' } \\
\text { R: 5'-GCGTCGTTGTTGCGGTTA-3' }\end{array}$ & 356 & $\begin{array}{l}58.61 \\
59.07\end{array}$ \\
\hline PAX2 & $\begin{array}{l}\text { F: 5'-CAGAGTGGCGTGGACAGTT-3' } \\
\text { R: 5'-GAATCTCCAAGCCTCGTTGTAG-3' }\end{array}$ & 438 & $\begin{array}{l}59.93 \\
58.81\end{array}$ \\
\hline FN1 & $\begin{array}{l}\text { F: 5'-CCGAGGAAGGAGAGCAGAAT-3' } \\
\text { R: 5'-CCAGCGAACGACAATAGAAGT-3' }\end{array}$ & 113 & $\begin{array}{l}58.88 \\
58.39\end{array}$ \\
\hline CD44 & $\begin{array}{l}\text { F: 5'-TGGAGAAGAATGGTCGCTACA-3' } \\
\text { R: 5'-AGGTGTTGGATGTGAGGATGT-3' }\end{array}$ & 228 & $\begin{array}{l}58.82 \\
59.01\end{array}$ \\
\hline PPARG & $\begin{array}{l}\text { F: 5'-CCACTATGGAGTTCATGCTTGT-3' } \\
\text { R: 5'-AACCTGATGGCATTATGAGACA-3' }\end{array}$ & 183 & $\begin{array}{l}58.39 \\
57.49\end{array}$ \\
\hline LPL & $\begin{array}{l}\text { F: 5'-CCGACAGGATTACAGGAGGAA-3' } \\
\text { R: 5'-TGTGGTTGAAGTGACAGTTAGC-3' }\end{array}$ & 141 & $\begin{array}{l}58.89 \\
58.80\end{array}$ \\
\hline AFP & $\begin{array}{l}\text { F: 5'-GACCTTCCGAGCCATAAC-3' } \\
\text { R: 5'-CAATGACCAAGTTCAAGTGT-3' }\end{array}$ & 243 & $\begin{array}{l}54.81 \\
54.03\end{array}$ \\
\hline ALB & $\begin{array}{l}\text { F: 5'-ATCTCACTAAGGTCCACAAG-3' } \\
\text { R: 5'-TCCAACACAGGCTTATCAC-3' }\end{array}$ & 145 & $\begin{array}{l}54.08 \\
54.79\end{array}$ \\
\hline SOX9 & $\begin{array}{l}\text { F: 5'- ACCGCCTTGTCGTTAGACTG-3' } \\
\text { R: 5'-GAATCTCCATCGTCCTCCAC-3' }\end{array}$ & 116 & $\begin{array}{l}60.04 \\
57.48\end{array}$ \\
\hline COL-2 & $\begin{array}{l}\text { F: 5'-CTCAAGTCCCTCAACAACCAG-3' } \\
\text { R: 5'-AGTCTCCGCTCTTCCACTCA-3' }\end{array}$ & 118 & $\begin{array}{l}58.50 \\
60.25\end{array}$ \\
\hline GAPDH & $\begin{array}{l}\text { F: 5'-CACTGTCCACGCCATCACT-3' } \\
\text { R: 5'-CCTGTTGCTGTAGCCGAATT-3' }\end{array}$ & 442 & $\begin{array}{l}60.00 \\
58.55\end{array}$ \\
\hline
\end{tabular}

F, forward; R, reverse.

in culture medium. While the cells in the induced group were induced to differentiate into adipogenic by culturing in DMEM/F12 supplemented with $10 \%$ FBS, 1 mM dexamethasone, $200 \mu \mathrm{M}$ indomethacin, $0.5 \mathrm{mM}$ IBMX and $10 \mu \mathrm{M}$ insulin. Two weeks later, cells in the two groups were detected by staining with Oil Red O.

Hepatocellular differentiation. The sheep MMSCs were seeded and separated into two groups, as described above. Upon reaching 60-70\% confluence, cells in the control group were maintained in culture medium. While the cells in the induced group were induced to differentiate into hepatocellular by culturing in DMEM/F12 supplemented with 5\% FBS, $100 \mu \mathrm{g} / \mathrm{ml}$ streptomycin, $100 \mathrm{IU} / \mathrm{ml}$ penicillin, $20 \mathrm{ng} / \mathrm{ml}$ hepatocyte growth factor, $40 \mathrm{nmol} / \mathrm{ml}$ dexamethasone, $1 \%$ ITS liquid media supplement, $10 \mathrm{ng} / \mathrm{ml}$ interleukin- 6 and $20 \mathrm{ng} / \mathrm{ml}$ epidermal growth factor. Two weeks later, cells in the two groups were detected by staining with periodic acid-Schiff stain (PAS).

Chondrogenic differentiation. The sheep MMSCs were seeded and separated into two groups as described above. Upon reaching 50-60\% confluence, cells in the control group were maintained in culture medium. While the cells in the induced group were induced to differentiate into chondrogenic cells by culturing in DMEM/F12 supplemented with $10 \%$ FBS,
$1 \%$ ITS, $50 \mu \mathrm{g} / \mathrm{ml}$ L-proline, $0.1 \mu \mathrm{m}$ dexamethasone, $0.9 \mathrm{mM}$ sodium pyruvate, $50 \mathrm{ug} / \mathrm{ml} \mathrm{L}$-ascorbic acid and $10 \mathrm{ng} / \mathrm{ml}$ transforming growth factor- $\beta 3$. Two weeks later, cells in the two groups were detected by staining with Alcian blue.

Statistical analysis. Statistical analyses of the data were performed with a one-way analysis of variance, followed by the Tukey-Kramer honest significant difference test for the three sets of results. $\mathrm{P}<0.01$ was considered to indicate a statistically significant difference. Statistical analyses were performed using JMP ${ }^{\circledR}$ Statistical Discovery Software (version 9.2; SAS Institute, Inc., Cary, NC, USA).

\section{Results}

Isolation, culture and morphology of MMSCs. The cells isolated from the kidney adhered to the culture plates with the initially morphology of round or irregular shape and started to elongate after $48 \mathrm{~h}$. The cells displayed a fibroblast-like morphology (Fig. 1) and grew to 80-90\% confluence after five days (Fig. 1A). The isolated primary MMSCs were mixed with blood cells, fibroblast cells and epithelial cells and proliferated readily, after P3-4, other cells detached and were eliminated from the population and which displayed a unique vortex shape (Fig. 1B). The cells showed no obvious morphological differences, and cellular morphology remained stable among 

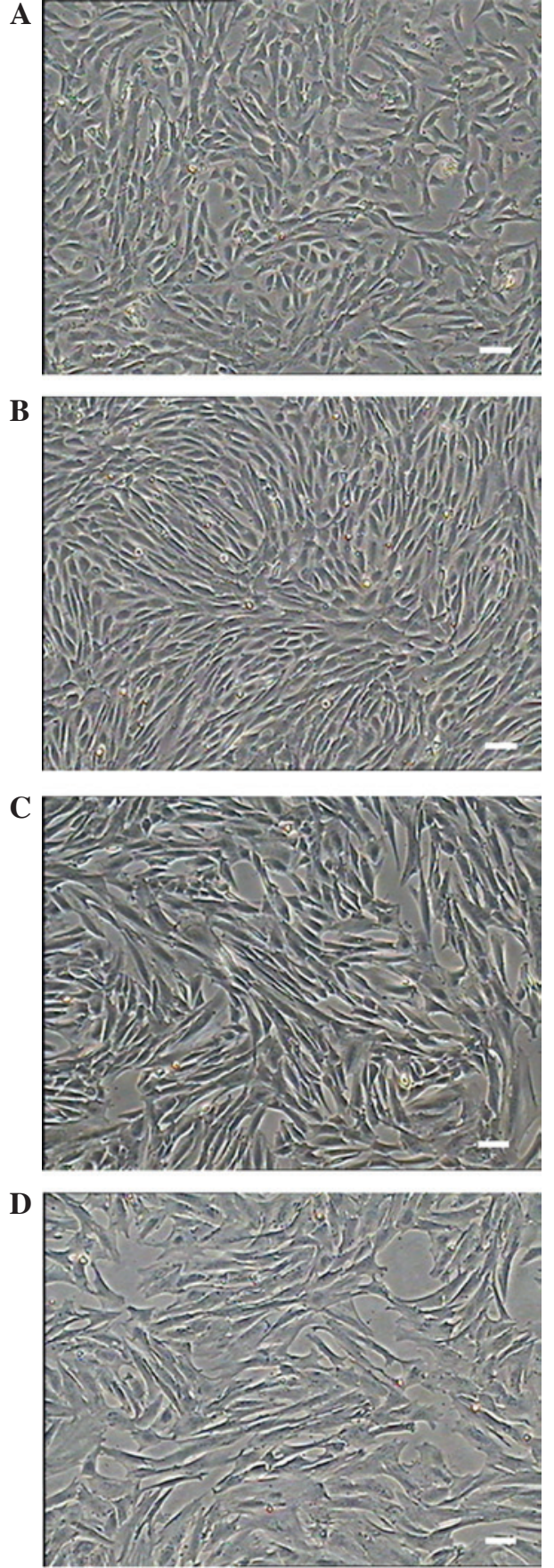

Figure 1. Morphology of primary cultured and subcultured sheep metanephric mesenchymal stem cells (MMSCs). (A) On day 5 of culture, MMSCs had a distinct 'shuttle' shape with clear boundaries and grew slowly. (B) MMSCs at P3. Cells were arranged like fibroblasts and grew in a vortex pattern. (C) MMSCs at P10. (D) MMSCs at P21 appeared senescent (scale bar, $100 \mu \mathrm{m}$ ).

successive passages (Fig. 1C). The cells were cultured to passage 16, with the majority of cells displaying signs of senescence, such as slow proliferation and blebbing. These phenomena were consistent with the PDT statistical analysis and growth curve (Fig. 2). As the increased passage, nearly all the cells flat grown on the culture plates without replete cytoplasm (Fig. 1D).

Self-renewal and proliferation assays. The growth curve of MMSCs from three different passages appeared as typically sigmoidal, which consisted of a latent phase, a logarithmic

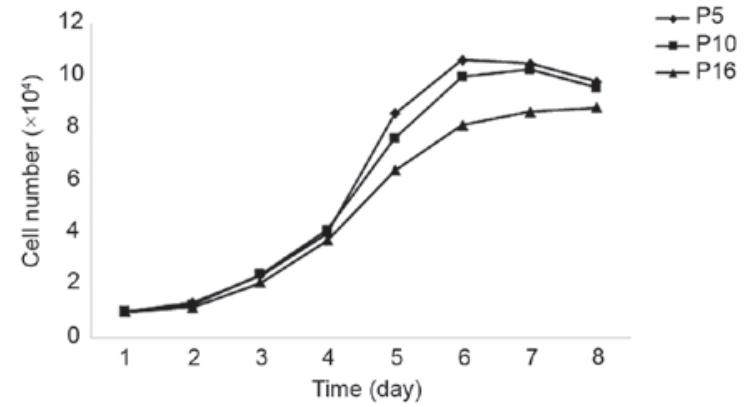

Figure 2. Growth curves of sheep metanephric mesenchymal stem cells (MMSCs). The growth curves of P5, P10 and P16 MMSCs were all typically sigmoidal, with cell density reflected by the vertical axis. The growth curve consisted of a latent, logarithmic and plateau phase. The population doubling times were $\sim 33.32,35.33$ and $47.04 \mathrm{~h}$ at P5, P10 and P16, respectively.

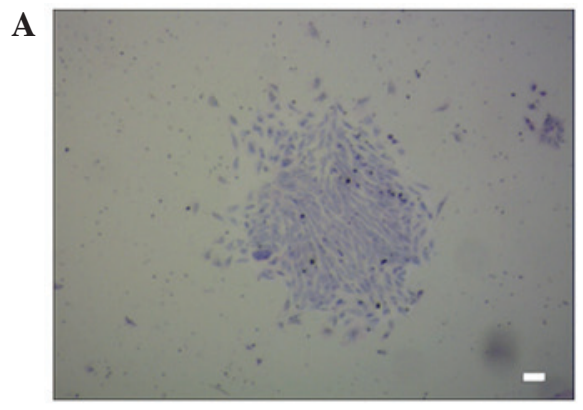

B

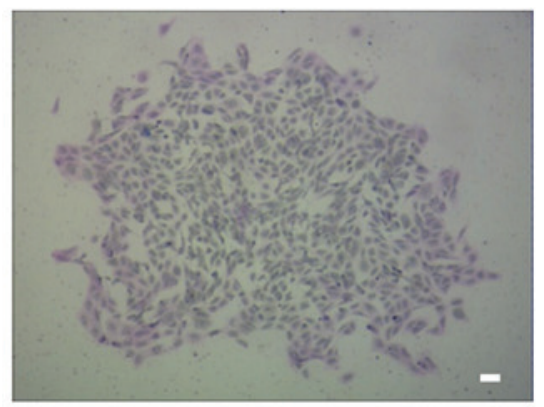

C

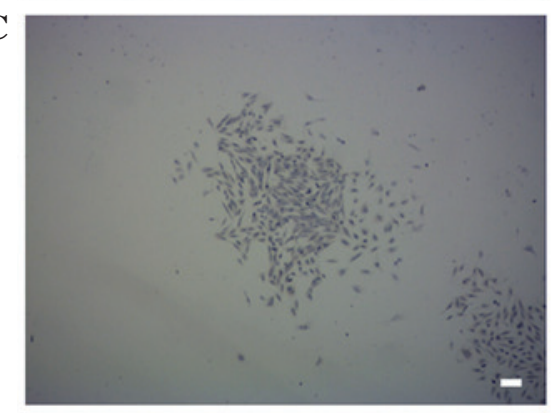

D

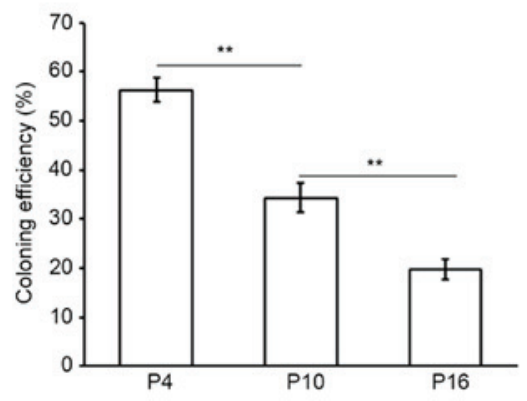

Figure 3. Colony forming efficiency of metanephric mesenchymal stem cells (MMSCs). Colonies with the morphology of MMSCs were cultured for 14 days. (A) P4, (B) P10 and (C) P16 (stain, Giemsa; scale bar, $100 \mu$ m). (D) Bar chart showing the cloning rates for different passages of MMSCs $\left({ }^{* *} \mathrm{P}<0.01\right)$. 


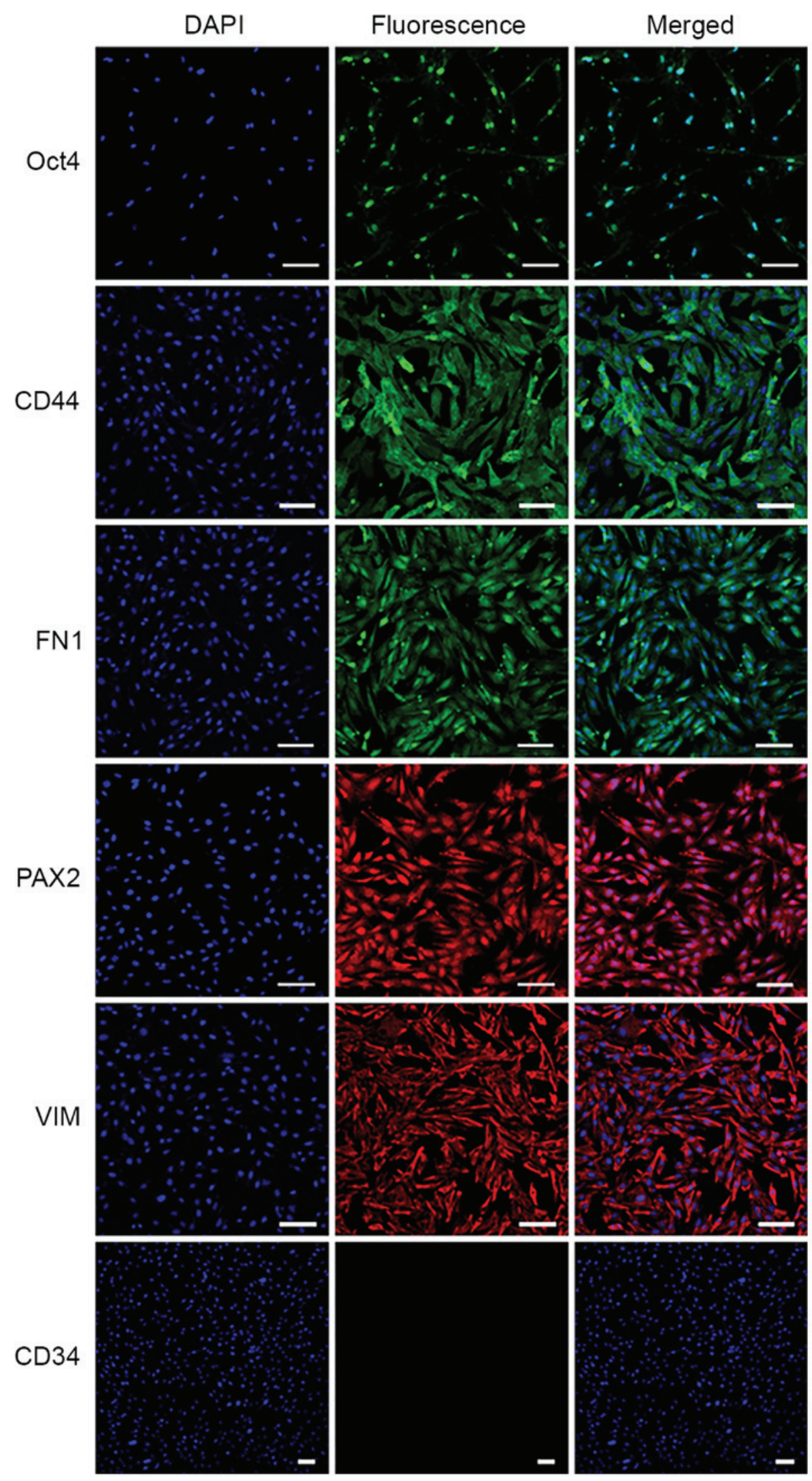

Figure 4. Detection of metanephric mesenchymal stem cell markers by immunofluorescence staining. The results show that OCT4, FN1, PAX2, CD44 and VIM are positively expressed, while CD34 is negative (scale bar, $100 \mu \mathrm{m}$ ).

phase and a plateau phase (Fig. 2). The PDTs were 33.32 , 35.33 and $47.04 \mathrm{~h}$ at P5, P10 and P16, respectively.
Colony formation of MMSCs from three different passages was evaluated by staining with Giemsa after two weeks. 


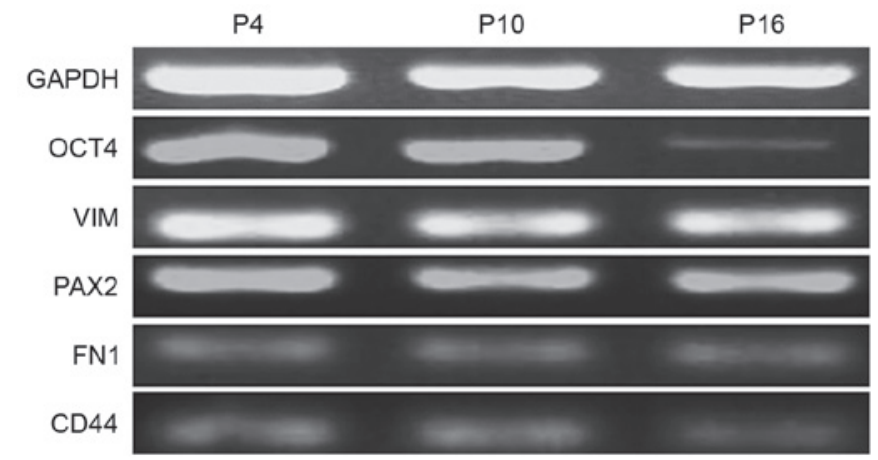

Figure 5. Detection of metanephric mesenchymal stem cell (MMSC) markers by reverse transcription-quantitative polymerase chain reaction. Analysis showed that different passages MMSCs expressed OCT4, VIM, PAX2, FN1 and CD44. GAPDH served as the internal control.

The colony-forming efficiency rates of the MMSCs at P4, 10 and 16 were $56.33 \pm 2.52,34.33 \pm 3.06$ and $19.67 \pm 2.08 \%$, respectively (Fig. 3). P4 MMSC proliferation capability was significantly higher than $\mathrm{P} 10$ and $\mathrm{P} 16(\mathrm{P}<0.01)$, and $\mathrm{P} 10$ was also significantly higher than $\mathrm{P} 16$ ( $\mathrm{P}<0.01$; Fig. 3D). These results suggest that the proliferation capacity of the cultured MMSCs declined significantly in a passage-dependent manner (Fig. 3).

\section{Characterization of MMSCs}

Markers of MMSCs. The specific markers of MMSCs were detected by immunofluorescence and RT-PCR analyses. The results of immunofluorescence showed that the MMSCs expressed Oct-4, VIM, CD44, FN1 and PAX2, but was negative for CD34 expression (Fig. 4). Similarly, the results of RT-PCR showed that MMSCs positively expressed Oct-4, CD73, CD44, PAX2 and VIM (Fig. 5).

Karyotype analysis. The sheep MMSCs were diploid $(2 \mathrm{n}=54)$. The sex chromosome type is XY (Fig. 6). In this study, the MMSCs chromosome numbers were calculated in 100 spreads per passage of P1-P20 to count the diploid rates. The results showed diploid cells accounted for $95 \%$, implying that the cultured cells possessed of genetic stability.

Adipogenic differentiation of MMSCs. When the MMSCs were cultured in adipogenic inducing medium, the morphology of cells changed slowly from a shuttle shape to an oblate shape and the cytoplasm contained numerous tiny lipid droplets after 7 days (Fig. 7). With the induction time extended to 12 days, the tiny lipid droplets aggregated to form an increased number of larger droplets (Fig. 7B). Adipogenic differentiation of MMSCs was detected by Oil Red O staining (3). The MMSCs cultured in complete medium as a control group were negative for Oil Red O staining (Fig. 7A).

RT-PCR results showed that after incubation with adipogenic inducing medium for 12 days the cells expressed the adipocyte-specific genes peroxisome proliferator-activated receptor-gamma and lipoprotein lipase, while the cells in the control group were negative for expression of these genes (Fig. 7C).

Hepatocellular differentiation of MMSCs. After incubating the MMSCs in hepatocellular medium for 7 days, the cells

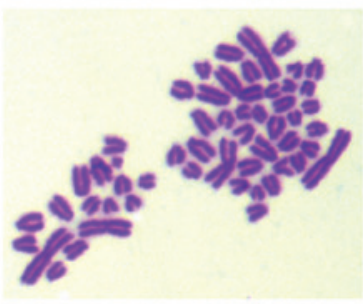

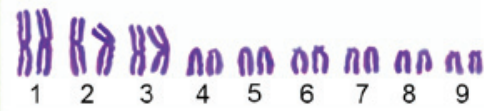

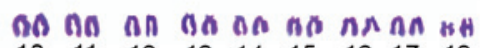

$\begin{array}{lllllllll}10 & 11 & 12 & 13 & 14 & 15 & 16 & 17 & 18\end{array}$

กล ถ⿻

$\begin{array}{lllllllll}19 & 20 & 21 & 22 & 23 & 24 & 25 & 26 & \mathrm{XY}\end{array}$

Figure 6. Chromosomes at metaphase (left) and karyotype (right) of sheep metanephric mesenchymal stem cells (magnification, x1,000). The chromosome number of sheep was $2 \mathrm{n}=54$, whilst the sex chromosome type was XY.

displayed obvious morphological changes, with a small population of small round-shaped cells observed (Fig. 8). After 14 days of differentiation, the cells showed a rising/piled morphology with light nuclei and dark cytoplasm that were stained with PAS (Fig. 8B) (23). The control group cells cultured in complete medium showed no such changes (Fig. 8A).

To evaluate the characterization of the MMSC-derived hepatocytes, two typical markers of hepatic cell gene expression were examined at the mRNA level. The RT-PCR results showed that the induced cells expressed typical markers of hepatic cells, such as alpha-fetoprotein and albumin (Fig. 8C), while the control group cells cultured in complete medium expressed no hepatic markers.

Chondrogenic differentiation of MMSCs. The sheep MMSCs were cultured in chondrogenic medium, and growth slowed. The MMSCs showed obvious morphological changes and formed small colonies after culture in chondrogenic medium for 12 days (Fig. 9). After 20 days of differentiation, Alcian blue staining revealed an increased number and size of colonies (Fig. 9B) (24). The control group cells cultured in complete medium showed no such effects (Fig. 9A).

RT-PCR was performed to analyze the chondrogenic differentiation of MMSCs. The results showed cartilage-specific genes sex determining region Y-box 9 and collagen type II were optimistic expressed in the induced group, but negatively expressed in the control group (Fig. 9C).

\section{Discussion}

In the present study, we successfully isolated MMSCs from the kidneys of six-week-old sheep fetuses. In addition, we observed the MMSCs isolated from six- and 10-week-old fetuses with significant differences in cell viability (data not shown). MMSCs were isolated from the six- and 10-week-old fetus kidneys, and the cell adherence of six-week-old MMSCs was more efficient than the 10 -week-old cells, which demonstrated that younger animals were more suitable for separating the MMSCs.

Previous studies have demonstrated that MMSCs express the stem cell marker Oct-4, which usually is associated with stem cell self-renewal and maintaining pluripotency $(25,26)$. In addition, MMSCs were shown to differentiate in vitro into adipocytes, hepatocytes and chondrocytes.

We detected the protein expression of VIM, CD44, PAX2 and FN1 in MMSCs using immunofluorescence and mRNA expression of VIM, CD44, PAX2 and CD73 using 
A

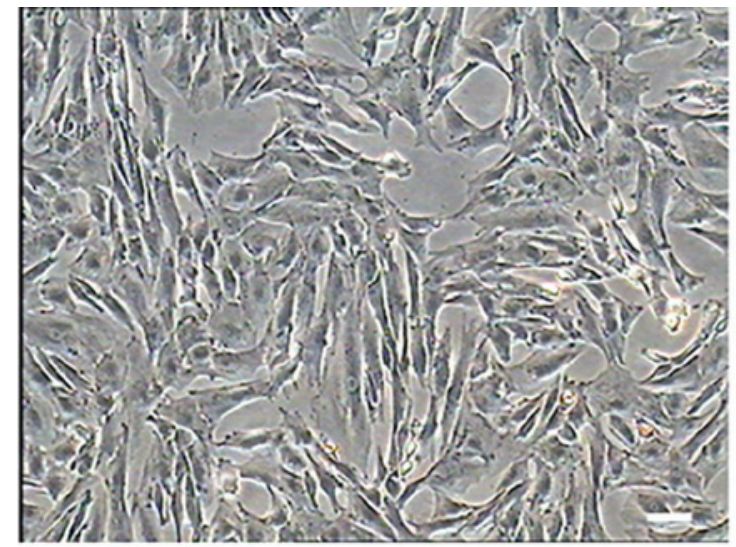

B
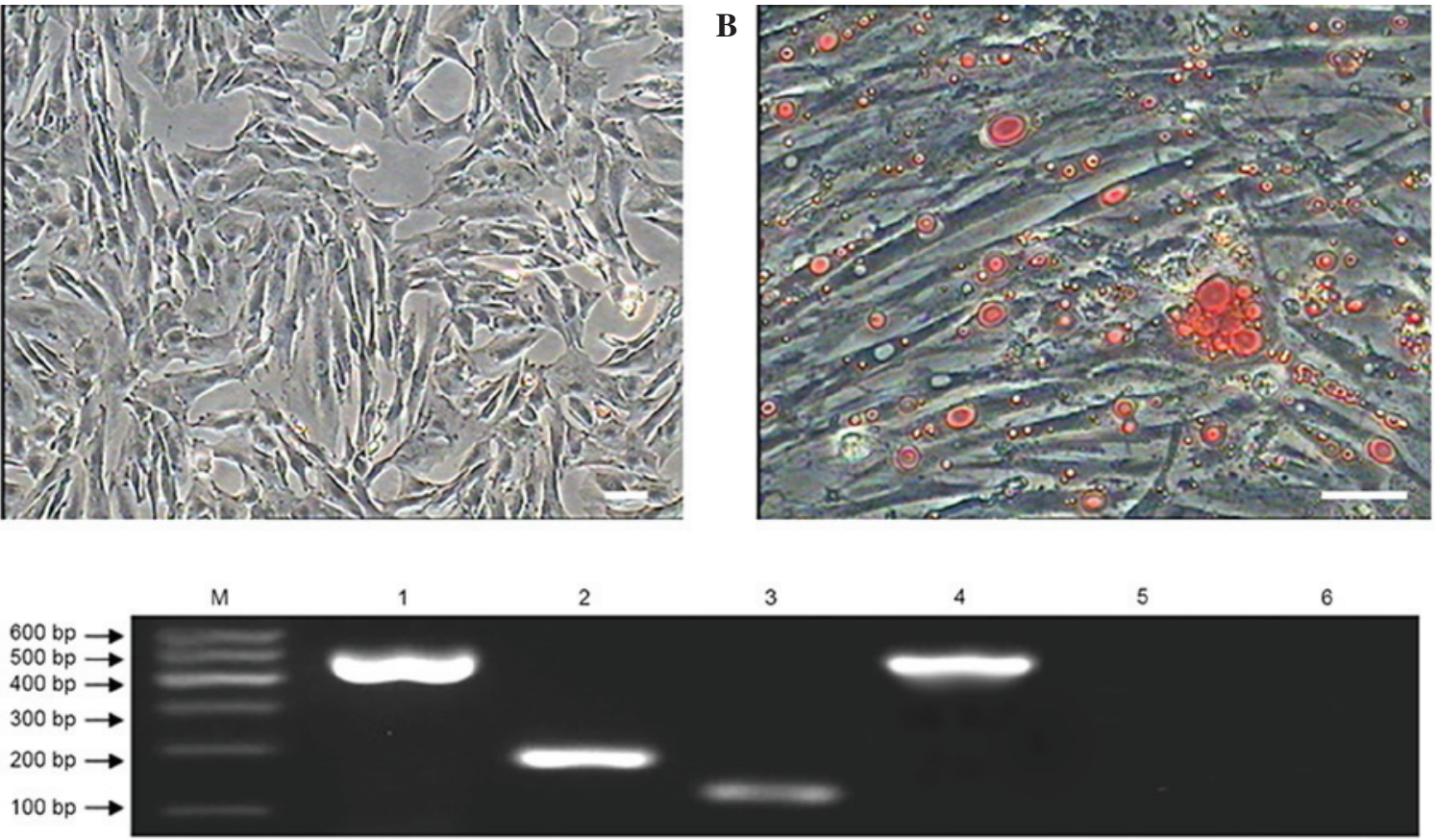

Figure 7. Adipogenic differentiation of sheep metanephric mesenchymal stem cells (MMSCs). (A) As a negative control, cells cultured in complete medium showed no changes in morphology and were negative for Oil Red O staining. (B) After induction for 12 days, MMSCs became fibroblast-like to oblate and formed numerous intracellular lipid droplets. Lipid droplets were stained with Oil Red O (scale bar, $100 \mu \mathrm{m}$ ). (C) Expression of adipocyte-specific genes LPL and PPARG were detected by reverse transcription-quantitative polymerase chain reaction in the induced group after induction for 12 days. Adipocyte-specific genes were not expressed in the control group. Lane 1: GAPDH served as the internal control in the inducted group; lane 2: PPARG was positive in the inducted group; lane 3: LPL was positive in the inducted group; lane 4: GAPDH served as the internal control in the control group; lane 5: PPARG was negative in the control group; lane 6: LPL was negative in the control group.

$\mathbf{A}$

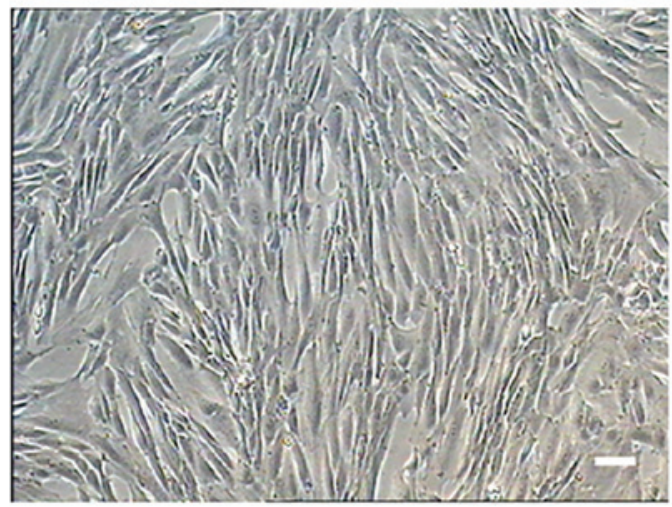

B

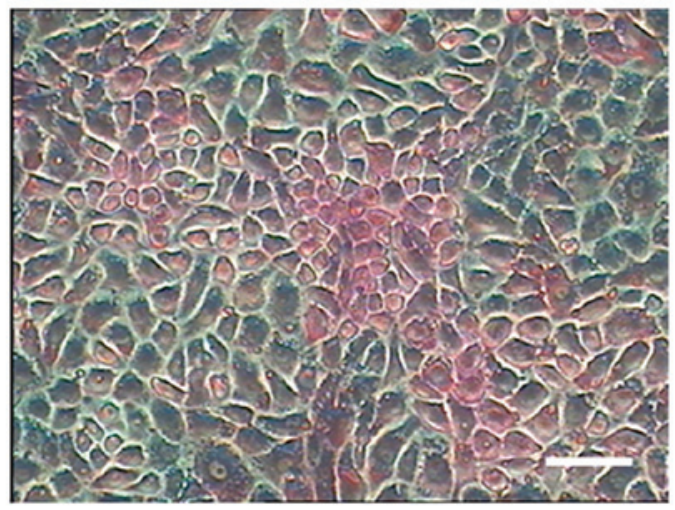

3

4

5

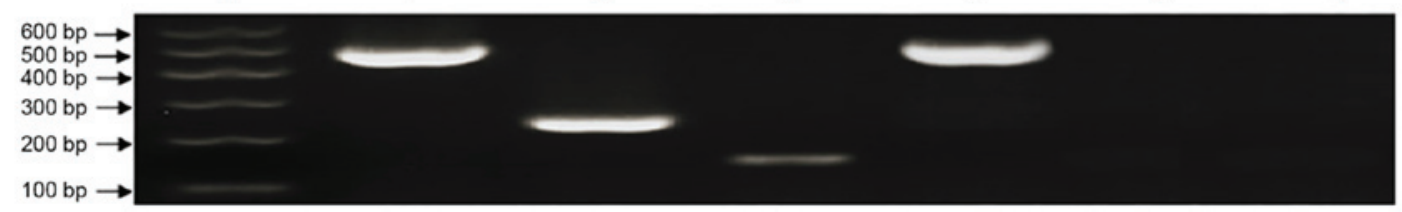

Figure 8. Hepatocellular differentiation of metanephric mesenchymal stem cells (MMSCs). (A) As a negative control, cells cultured in complete medium showed no changes in morphology and were negative for periodic acid-Schiff staining (PAS) staining. (B) After 14 days of differentiation, the cells displayed a rising/piled morphology with dark cytoplasm and light nuclei that were stained with PAS (scale bar, $100 \mu \mathrm{m}$ ). (C) Expression of hepatocyte-specific genes AFP and ALB were detected by reverse transcription-quantitative polymerase chain reaction in the induced group after induction for 14 days. Hepatocyte-specific genes were not expressed in the control group. Lane 1: GAPDH served as the internal control in the inducted group; lane 2: AFP was positive in the inducted group; lane 3: ALB was positive in the inducted group; lane 4: GAPDH served as the internal control in the control group; lane 5: AFP was negative in the control group; lane 6: ALB was negative in the control group.

RT-PCR. VIM is a type III intermediate filament protein that is expressed in mesenchymal cells (27). CD44, a receptor for hyaluronic acid and a protein coding gene, encodes a cell-surface glycoprotein involved in cell adhesion, cell-cell 
A

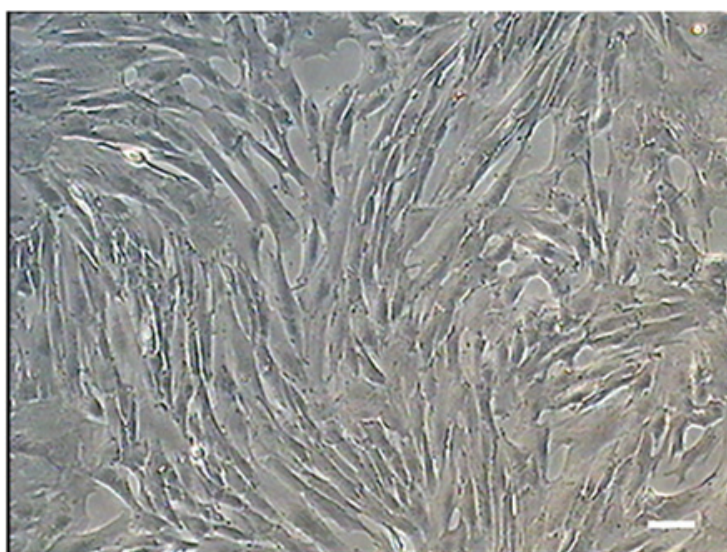

B

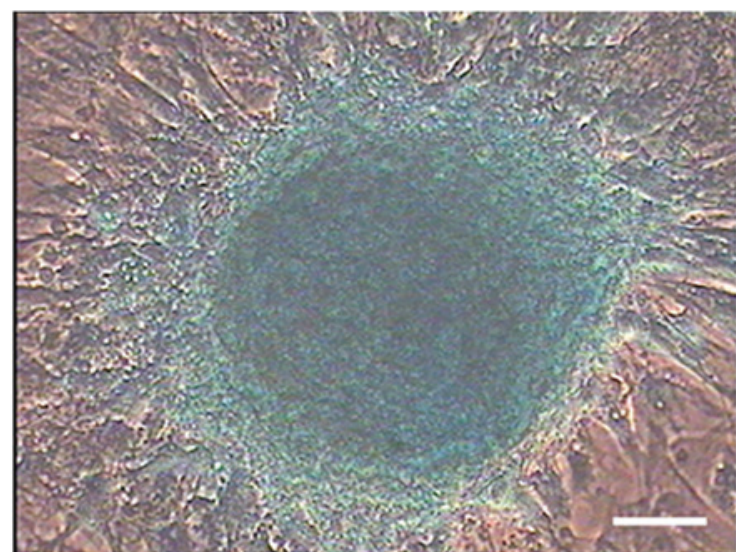

3

4

2
C

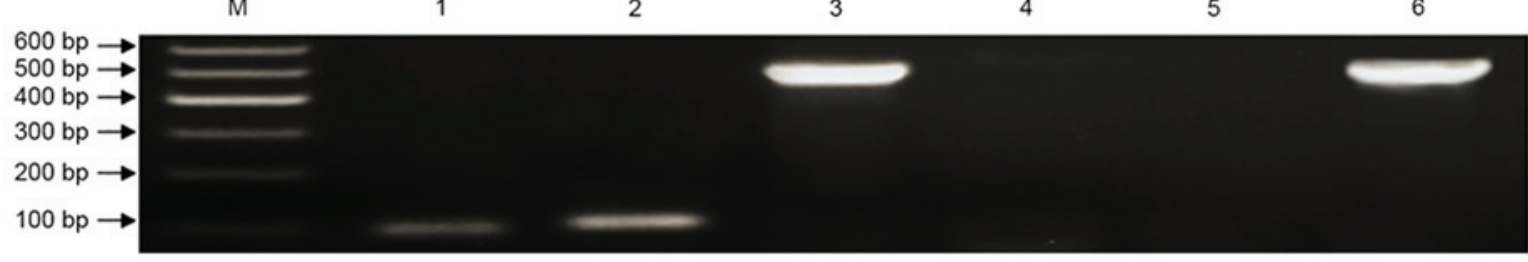

Figure 9. Chondrogenic differentiation of metanephric mesenchymal stem cells (MMSCs). (A) As a negative control, cells cultured in complete medium showed no changes in morphology and were negative for Alcian blue staining. (B) After 20 days of differentiation, the cells showed obvious morphological changes and formed colonies that were stained with Alcian blue (scale bar, $100 \mu \mathrm{m}$ ). (C) Expression of cartilage-specific genes SOX9 and COL-2 were detected by reverse transcription-quantitative polymerase chain reaction in the induced group after induction for 20 days. Cartilage-specific genes were not expressed in the control group. Lane 1: SOX9 was positive in the inducted group; lane 2: COL-2 was positive in the inducted group; lane 3: GAPDH served as the internal control in the inducted group; lane 4: SOX9 was negative in the control group; lane 5: COL-2 was negative in the control group; lane 6: GAPDH served as the internal control in the control group.

interactions and migration such as collagens, osteopontin and matrix metalloproteinases (28). PAX2, a protein coding gene, expressed in fetal kidneys, throughout the branching ureteric bud Wolffian and Mullerian ducts, has an essential role in urogenital tract development (29). Transcription factor of PAX2 that may have a key function in kidney cell differentiation (29). In addition, it plays a critical role in the branching ureteric the development of renal epithelium, dysregulated during early stages of nephrogenesis (29). FN1 encodes fibronectin, a glycoprotein present in extracellular matrix and in a dimeric or multimeric form at the cell surface (30). FN is involved in cell adhesion and migration processes. CD73 (Ecto-5'-nucleotidase) is a multifunctional ectoenzyme that metabolizes adenosine 5'-monophosphate into adenosine (31). CD73 is also a glycosyl-phosphatidylinositol-conjugated, membrane-bound glycoprotein. CD73 is a signaling molecule and has been shown to participate in purine salvaging and purinergic cascades that lead to cell metabolism (31). This pathway has been shown to be important in immunological signaling and is involved in signal transduction and cell adhesion (31). In summary, the specific markers of MSCs and kidney were shown to be positively expressed in MMSCs by immunofluorescence and RT-PCR analyses.

Twice diploid karyotype and the stably characteristic chromosome number, shape and structure are the prerequisite for the cell growth and functioning (32). Therefore, karyotype analysis is a simple and practical method for distinguishing normal cells from variants. Sheep have 27 pairs of chromosomes, with sex chromosomes X and Y (33). The sheep MMSCs cultured in the present study were all normal diploids. In our experiment, we found that the sheep MMSCs were diploid $(2 n=54, X Y)$.

The multipotency of stem cells is an important prerequisite for autologous cell therapy (34). As they are conducive to mass preparation, MMSCs can serve as ideal experimental cells for tissue engineering research (8). The developmental repertoire of tissue stem cells in vivo is subject to the control of gene-encoded transcription factors and extracellular signals (35); however, the differentiation mechanism remains unclear in vitro.

In the present study, we induced sheep MMSCs to differentiate into adipocytes, hepatocytes and chondrocytes, under different induction conditions. The various inducing factors can affect the direction of differentiation of the MMSCs, which originate from mesoblastoma and can be differentiated into endoderm and ectoderm cell types in vitro. Therefore, the multi-potentiality and convenient procurement of the MMSCs cultured herein suggest that they may offer a potential option for tissue engineering and cellular transplantation therapy (10).

Despite the multi-lineage differentiation of the sheep MMSCs being successful in vitro, the technical difficulties and safety concerns related to using the cells for tissue recovery in vivo remain unsolved. Therefore, additional studies are needed with regard to using these cells for future research and therapy.

In conclusion, MMSCs were isolated from the kidney of six-week-old sheep fetuses, and underwent analyses of their self-renewal ability and differentiation potential in vitro. These results suggest the potential utility of the sheep MMSCs as a source of stem cells for regenerative medical therapies. 


\section{Acknowledgements}

The present study was supported by the Agricultural Science and Technology Innovation Program (cxgc-ias-01), the National Natural Science Foundation of China (grant nos. 31201765 and 31272403; 31472064), the China Postdoctoral Science Foundation (grant no. 2015M571182) and the National Infrastructure of Animal Germplasm Resources (2014).

\section{References}

1. Bai C, Hou L, Ma Y, Chen L, Zhang M and Guan W: Isolation and characterization of mesenchymal stem cells from chicken bone marrow. Cell Tissue Bank 14: 437-451, 2013.

2. Gao Y, Zhu Z, Zhao Y, Hua J, Ma Y and Guan W: Multilineage potential research of bovine amniotic fluid mesenchymal stem cells. Int J Mol Sci 15: 3698-3710, 2014.

3. Li X, Gao Y, Hua J, Bian Y, Mu R, Guan W and Ma Y: Research potential of multi-lineage chicken amniotic mesenchymal stem cells. Biotech Histochem 89: 172-180, 2014.

4. Naghdi M, Tiraihi T, Namin SA and Arabkheradmand J: Transdifferentiation of bone marrow stromal cells into cholinergic neuronal phenotype: A potential source for cell therapy in spinal cord injury. Cytotherapy 11: 137-152, 2009.

5. Drost AC, Weng S, Feil G, Schäfer J, Baumann S, Kanz L, Sievert KD, Stenzl A and Möhle R: In vitro myogenic differentiation of human bone marrow-derived mesenchymal stem cells as a potential treatment for urethral sphincter muscle repair. Ann N Y Acad Sci 1176: 135-143, 2009.

6. Tamama K, Sen CK and Wells A: Differentiation of bone marrow mesenchymal stem cells into the smooth muscle lineage by blocking ERK/MAPK signaling pathway. Stem Cells Dev 17: 897-908, 2008

7. Shafiee A, Kabiri M, Ahmadbeigi N, Yazdani SO, Mojtahed M, Amanpour S and Soleimani M: Nasal septum-derived multipotent progenitors: A potent source for stem cell-based regenerative medicine. Stem Cells Dev 20: 2077-2091, 2011.

8. Bai C, Li X, Hou L, Zhang M, Guan W and Ma Y: Biological characterization of chicken mesenchymal stem/progenitor cells from umbilical cord Wharton's jelly. Mol Cell Biochem 376: 95-102, 2013

9. Gao Y, Bai C, Xiong H, Li Q, Shan Z, Huang L, Ma Y and Guan W: Isolation and characterization of chicken dermis-derived mesenchymal stem/progenitor cells. Biomed Res Int 2013: 626258, 2013.

10. Osafune K: Cell therapy for kidney injury: Different options and mechanisms-kidney progenitor cells. Nephron Exp Nephrol 126 64, 2014.

11. Liu L, Chen D, Yi ZW, Liu XH, Wu XC, Dang XQ, He QN, He XJ and Mo SH: Nephroprotective effects of subcapsular transplantation of metanephric mesenchymal cells on gentamicin-induced acute tubular necrosis in rats. World J Pediatr 8: 156-163, 2012.

12. Oliver JA, Barasch J, Yang J, Herzlinger D and Al-Awqati Q: Metanephric mesenchyme contains embryonic renal stem cells. Am J Physiol Renal Physiol 283: F799-F809, 2002.

13. Al-Awqati Q and Oliver JA: Stem cells in the kidney. Kidney Int 61: 387-395, 2002.

14. Zhang Y, Jiang H, Bai Y, Liang J, Zhao A and Dou L: Research progress of bone marrow-derived mesenchymal stem cells in the treatment of chronic kidney disease. Hainan Med J 27: 968-972, 2016.

15. Xiangyu Z, Guangyuan Z, Zhongliang C, Deming Y, Tao D, Guanqun J, Shuai M, Guohua L, Mujun L and Yingjian Z: Microvesicles derived from human Wharton's Jelly mesenchymal stromal cells ameliorate renal ischemia-reperfusion injury in rats by suppressing CX3CL1. Stem Cell Res Ther 5: 40, 2014.

16. Yeo RWY, Lai RC, Tan KH and Lin SK: Exosome: A novel and safer therapeutic refinement of mesenchymal stem cell. Exosomes Microvesicles 1: 7, 2013.

17. Dressler GR: Advances in early kidney specification, development and patterning. Development 136: 3863-3874, 2009.
18. McManus LM and Mitchell RN (eds): Pathobiology of Human Disease. 1st edition. Elsevier Science Publishing Co., Inc., Amsterdam, 2014.

19. Barber C, Garnham L, Lovell S, Camus H and Persaud M: Galvanising the role of learning disability nursing. Br J Nurs 17 : S3, 2008.

20. Baran SW and Ware CB: Cryopreservation of rhesus macaque embryonic stem cells. Stem Cells Dev 16: 339-344, 2007.

21. Sun CC, Su Pang JH, Cheng CY, Cheng HF, Lee YS, Ku WC, Hsiao $\mathrm{CH}$, Chen JK and Yang CM: Interleukin-1 receptor antagonist (IL-1RA) prevents apoptosis in ex vivo expansion of human limbal epithelial cells cultivated on human amniotic membrane. Stem Cells 24: 2130-2139, 2006.

22. Kawarai S, Hashizaki K, Kitao S, Nagano S, Madarame H, Neo S, Ishikawa T, Furuichi M, Hisasue M, Tsuchiya R, et al: Establishment and characterization of primary canine hepatocellular carcinoma cell lines producing alpha-fetoprotein. Vet Immunol Immunopathol 113: 30-36, 2006.

23. Yang Z, Sun B, Zhao X, Shao B, An J, Gu Q, Wang Y, Dong X, Zhang Y and Qiu Z: Erythropoietin and erythropoietin receptor in hepatocellular carcinoma: Correlation with vasculogenic mimicry and poor prognosis. Int J Clin Exp Pathol 8: 4033-4043, 2015.

24. Karystinou A, Roelofs AJ, Neve A, Cantatore FP, Wackerhage $\mathrm{H}$ and De Bari C: Yes-associated protein (YAP) is a negative regulator of chondrogenesis in mesenchymal stem cells. Arthritis Res Ther 17: 147, 2015.

25. Babaie Y, Herwig R, Greber B, Brink TC, Wruck W, Groth D, Lehrach H, Burdon T and Adjaye J: Analysis of Oct4-dependent transcriptional networks regulating self-renewal and pluripotency in human embryonic stem cells. Stem Cells 25: 500-510, 2007.

26. Lee J, Kim HK, Rho JY, Han YM and Kim J: The human OCT-4 isoforms differ in their ability to confer self-renewal. J Biol Chem 281: 33554-33565, 2006.

27. Challa AA and Stefanovic B: A novel role of vimentin filaments: Binding and stabilization of collagen mRNAs. Mol Cell Biol 31: 3773-3789, 2011.

28. Vikesaa J1, Hansen TV, Jønson L, Borup R, Wewer UM, Christiansen J and Nielsen FC: RNA-binding IMPs promote cell adhesion and invadopodia formation. Embo J 25: 1456-1468, 2006.

29. Barua M, Stellacci E, Stella L, Weins A, Genovese G, Muto V, Caputo V, Toka HR, Charoonratana VT, Tartaglia M, Pollak MR: Mutations in PAX2 associate with adult-onset FSGS. J Am Soc Nephrol 25: 1942-1953, 2014.

30. Purushothaman A, Bandari SK, Liu J, Mobley JA, Brown EE and Sanderson RD: Fibronectin on the surface of myeloma cellderived exosomes mediates exosome-cell interactions. J Biol Chem 291: 1652-1663, 2016.

31. Garavaglia S, Bruzzone S, Cassani C, Canella L, Allegrone G, Sturla L, Mannino E, Millo E, De Flora A and Rizzi M: The high-resolution crystal structure of periplasmic Haemophilus influenzae NAD nucleotidase reveals a novel enzymatic function of human CD73 related to NAD metabolism. Biochem J 441: 131-141, 2012.

32. Ji M, Guan W, Gao Y, Li L, Bai C, Ma, Y and Li C: Cultivation and biological characterization of chicken primordial germ cells. Braz Arch Biol Technol: Feb 26, 2016 (Epub ahead of print).

33. Pauciullo A, Perucatti A, Cosenza G, Iannuzzi A, Incarnato D, Genualdo V, Di Berardino D and Iannuzzi L: Sequential cross-species chromosome painting among river buffalo, cattle, sheep and goat: A useful tool for chromosome abnormalities diagnosis within the family Bovidae. PloS One 9: e110297, 2014.

34. Nagoshi N, Shibata S, Kubota Y, Nakamura M, Nagai Y, Satoh E, Morikawa S, Okada Y, Mabuchi Y, Katoh H, et al: Ontogeny and multipotency of neural crest-derived stem cells in mouse bone marrow, dorsal root ganglia, and whisker pad. Cell Stem Cell 2: 392-403, 2008

35. Guilak F, Cohen D M, Estes BT, Gimble JM, Liedtke W and Chen CS: Control of stem cell fate by physical interactions with the extracellular matrix. Cell Stem Cell 5: 17-26, 2009. 